Original Research Paper

\title{
Prediction of Residual Axial Load Carrying Capacity of Reinforced Concrete (RC) Columns Subjected to Extreme Dynamic Loads
}

\author{
${ }^{1}$ Masoud Abedini, ${ }^{1}$ Azrul A. Mutalib, \\ ${ }^{2}$ Sudharshan N. Raman, ${ }^{1}$ Shahrizan Baharom and ${ }^{3}$ J. Sima Nouri \\ ${ }^{1}$ Department of Civil and Structural Engineering, \\ Universiti Kebangsaan Malaysia, 43600 UKM Bangi, Selangor, Malaysia \\ ${ }^{2}$ Department of Architecture, Universiti Kebangsaan Malaysia, 43600 UKM Bangi, Selangor, Malaysia \\ ${ }^{3}$ Departmant of Statistic, Tarbiat Modares University, Tehran, Iran
}

Article history

Received: 9-11-2016

Revised: 25-01-2017

Accepted: 03-05-2017

Corresponding Author: Masoud Abedini

Department of Civil and

Structural Engineering,

Universiti Kebangsaan

Malaysia, 43600 UKM Bangi,

Selangor, Malaysia

Email: masoud.a877@yahoo.com

\begin{abstract}
The evaluation of residual axial load carrying capacity of reinforced concrete (RC) columns to explosion load is significant for protection of buildings. The few investigations conducted on residual axial load carrying capacity of RC columns when subjected to blast loads. Therefore, the overall aim of this research is to generate equations on the blast capacity of axially and uniaxial loaded columns. In this study, an advanced nonlinear model is developed to study the residual axial load carrying capacity $\left(P_{\text {residual }}\right)$ of RC columns to explosion loads using Arbitary Lagrangian Eulerian (ALE) finite element technique in LS-DYNA 971. The ALE model represents the actual blast incident scenario and is validated with experimental study reported in the previous research. In order to derive the $P_{\text {residual }}$ empirical equations, intensive parametric studies are carried out to investigate the effects of column depth $(d)$, longitudinal reinforcement ratio $(\rho)$, transverse reinforcement ratio $\left(\rho_{s}\right)$, yield stress of longitudinal steel $\left(f_{y}\right)$, yield stress of transverse steel $\left(f_{y t}\right)$, column height $(H)$, column width $(w)$ and concrete strength $\left(f_{c}\right)$ on the residual axial capacity of RC columns. Based on numerical simulation data, nine empirical relations are suggested to predict residual axial capacity of RC columns. The validated equations can be used for quick assessment of existing RC columns when blast loading is required to be considered especially to evaluate the blast resistant capacity of a critical building such as military buildings, government assets and etc.
\end{abstract}

Keywords: Residual Axial Load Carrying Capacity, Arbitary Lagrangian Eulerian ( $A L E)$ Method, Explosion Load.

\section{Introduction}

In terms of structural stability of an RC structure, $\mathrm{RC}$ columns play a dominant role. Columns are one of the key load bearing elements that are highly susceptible to blast loads. It transmits the load, through compressive forces, from the upper portion of the structure to the ground. The resulting severe damages to columns may leads to failures of the supporting structure that are catastrophic in nature. One of the most useful pieces of information about the $\mathrm{RC}$ structures when subjected to extreme dynamic load would be the residual axial load carrying capacity of its columns. Each loading condition has its unique rate of loading. Explosion loads subject structures to significant loads applied at a very short period of time which produces strain rates between 1 and $1000 \mathrm{~s}^{-1}$ (Bischoff and Perry, 1991). The behavior of concrete under the effects of high strain rate has been extensively studied over the past few years. Malvar and Ross (1998) conducted that the compressive strength of concrete increased with the rate of loading. Compared to other materials, concrete exhibits higher strain rate sensitivity under blast loading, due to scale 
size of the heterogeneity (Weerheijm and Van Doormaal, 2007). Especially, the tensile strength exhibits a strong increase beyond loading rates in the order of $10 \mathrm{MPa} / \mathrm{s}$.

The residual axial capacity of a RC column can be determined through numerical analysis performed on the detailed finite element models of the columns. In this study, the residual axial capacity index $\left(P_{r}\right)$ was defined as the axial compression capacity of a column in damage conditions. Some articles used residual capacity of RC column to determine vulnerability and damage analysis of columns under blast loads (Mutalib and Hao, 2011; $\mathrm{Wu}$ et al., 2011; Fujikake and Aemlaor, 2013; Wijesundara and Clubley, 2015a; 2016). Shi et al. (2008) and Mutalib and Hao (2011) performed the special loading procedure that is used to assess the damage of RC columns based on the residual capacity of columns that represents in the Fig. 1.

The performance of RC columns during blast detonation has been investigated by a number of researchers over the past five decades (Mutalib and Hao, 2011; Cui et al., 2015; Shi and Stewart, 2015). Roller conducted a research to investigate the residual load capacity of exposed and hardened concrete columns when subjected to blast detonations (Roller et al., 2013). Jayasooriya evaluated the residual capacity of the RC columns based on localized material yielding (Jayasooriya et al., 2011). In their study, Maximum and minimum principle stress plots are used to determine the yield and post yield conditions of the material to identify the level of damage to the $\mathrm{RC}$ columns and then the effective undamaged cross-section areas of a column, after yielding of the materials, are used to determine the residual capacity. Bao investigated the dynamic responses and residual axial strength of $\mathrm{RC}$ columns with a parametric study (Bao and Li, 2010). This study identified the effects of RC columns' parameters such as reinforcement ratio, axial load ratio and column aspect ratio on blast response. The study proposed a formula to estimate the residual capacity ratio based on the mid-height displacement to height ratios. Wijesundara and Clubley (2015b) conducted a research to assessment the residual capacity of RC columns when subjected to internal blast loads.

The aim of this study is to estimating the formulae to predicting the residual axial capacity of RC columns when subjected to blast loads. The analysis is performed using LS-DYNA non-linear explicit FE code to provide numerical simulations of the residual capacity of RC column to explosion load. A finite element model of the RC columns is developed and numerical blast simulations were performed in this study to obtain the residual axial capacity of RC columns. Arbitary Lagrangian Eulerian (ALE) method is applied in the current study to simulate blast load effects on the RC column. The accuracy of the numerical models is verified using the findings of experimental data obtained by other researchers. By using the results of numerical study, analytical models on $\mathrm{RC}$ columns have been developed.
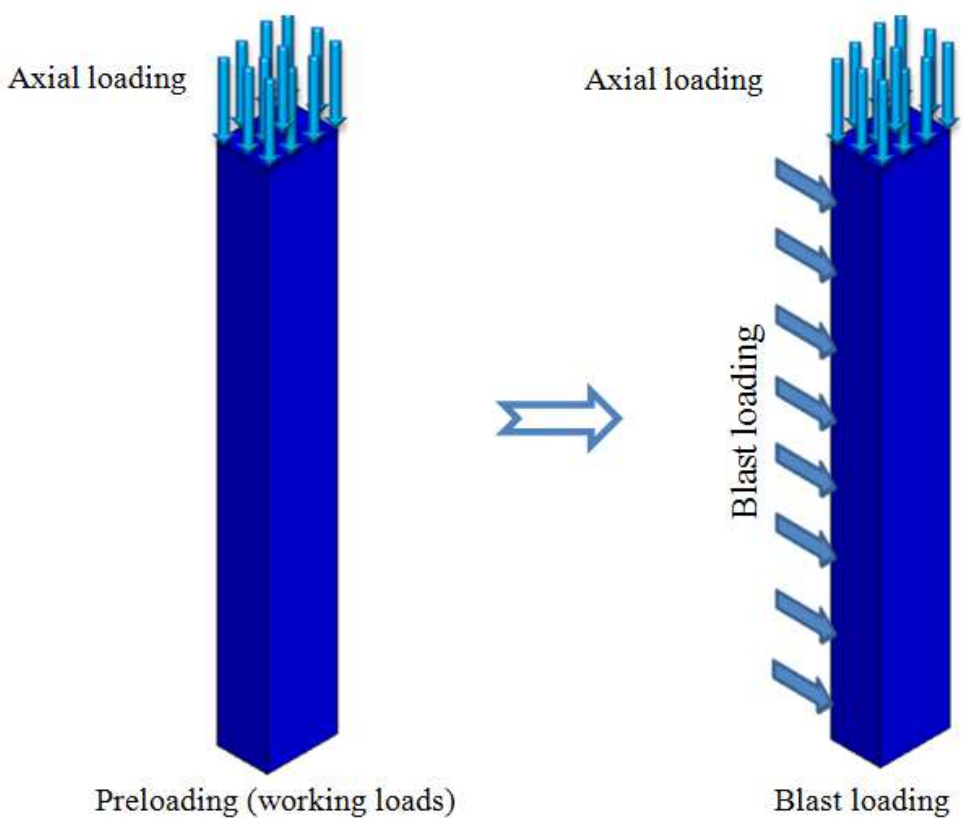

Blast loading

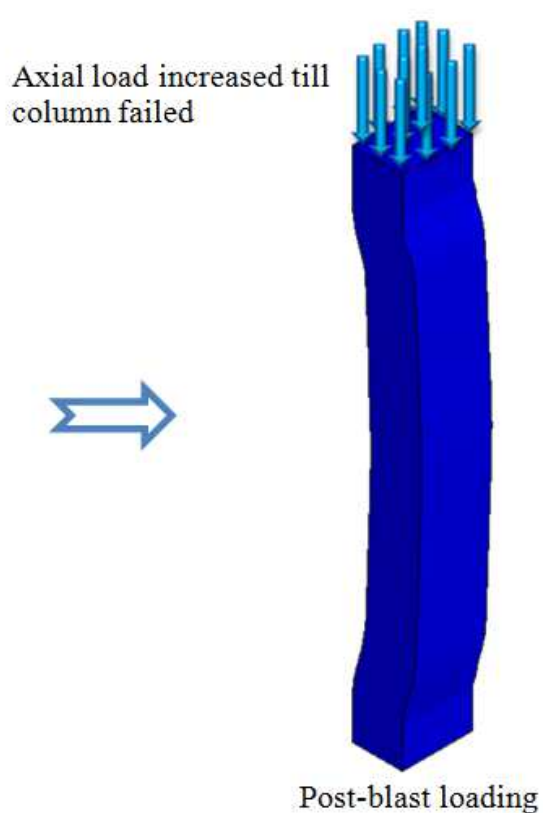

Post-blast loading

Fig. 1. Depiction of the special loading procedure that is used to assess the residual capacity of RC columns 

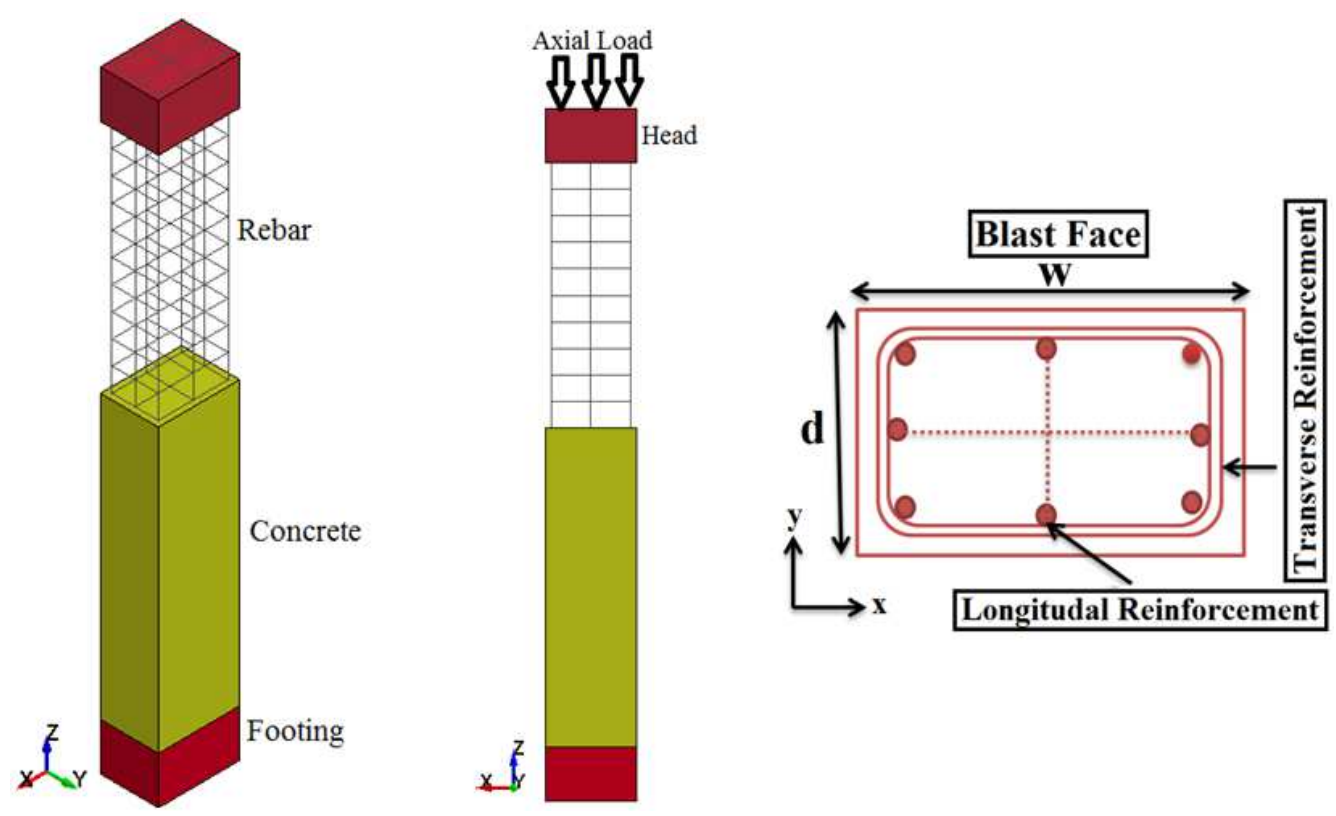

Fig. 2. Details of RC column

Table 1. Material properties of concrete and steel reinforcement

\begin{tabular}{lll}
\hline Material & Parameters & Value \\
\hline Concrete & Uniaxial compressive strength & $42 \mathrm{MPa}$ \\
& Mass density & $2400 \mathrm{~kg} / \mathrm{m}^{3}$ \\
& Poisson's ratio & 0.2 \\
Steel & Tensile stress at failure & $6.0 \mathrm{MPa}$ \\
Reinforcement & Young's Modulus & $200 \mathrm{GPa}$ \\
& Longitudinal Steel strength & $460 \mathrm{MPa}$ \\
& Transverse Steel strength & $250 \mathrm{MPa}$ \\
& Mass density & $7800 \mathrm{~kg} / \mathrm{m}^{3}$ \\
& Poisson's ratio & 0.3 \\
& Plastic strain at failure & 0.18 \\
\hline
\end{tabular}

\section{Finite Element Modeling of RC Column}

Figure 2 shows a numerical model constructed in the current study. The structure model consists of steel and concrete subjected to blast load. The longitudinal and transverse bars are represented as beam elements and concrete is represented as solid element. The concrete column was modeled using 50 $\mathrm{mm}$ eight node hexagonal constant stress solid elements with one point integration. $50 \mathrm{~mm}$ long beam elements are used for both vertical and the lateral reinforcements with $2 \times 2$ Gauss integration. The vertical reinforcements are defined as truss elements and the links are defined as a Hughes-Liu beam element with cross sectional integration (Flanagan and Belytschko, 1981). Both ends of the column are fixed to define the boundary conditions. All degrees of freedom at the bottom and top of the column are restrained, whilst only vertical displacements are permitted at the top. The axial load is applied on the top of column. The parameters for the material models are in Table 1 and the explosive charge is positioned at a distance of $500 \mathrm{~mm}$ from the $\mathrm{RC}$ column.

\section{Simulation of Blast Detonation}

Dynamic behavior of different engineering components subjected to blast loads can be investigated using either actual explosives or blast simulators (Ellingwood and Dusenberry 2005). Response of RC columns under blast effects can be examined using different techniques of load application. Arbitary Lagrangian Eulerian (ALE) method is applied in the current study. The ALE method is a complex method requiring modeling of the structure, the explosive material and the containing air domain as shown in Fig. 3.

In this method, explosive and air domain should be modeled in addition to concrete and reinforcement. The explosive charge is detonated within the air domain and the shock wave is transferred through air to contact the structure. The elements number in this method is very high, which requires a lot of time for processing and analyzing and needs a computer with very high specifications. The ALE algorithm simultaneously describes the motion of fluids and also shows the dynamic response of solids (Wang and Gadala, 1997; Stoker, 1999; Donea and Huerta, 2004; Haufe et al., 2004; Tai et al. 2011).

Fluid-Structure Interaction (FSI) between ALE (fluid) and lagrangian (structure) materials is defined by CONSTRAINED_LAGRANGE_IN_SOLID. The field of the air needs the BOUNDARY NON REFLECTING conditions, in order not to have the reflection of the wave at the boundary of the domain. 


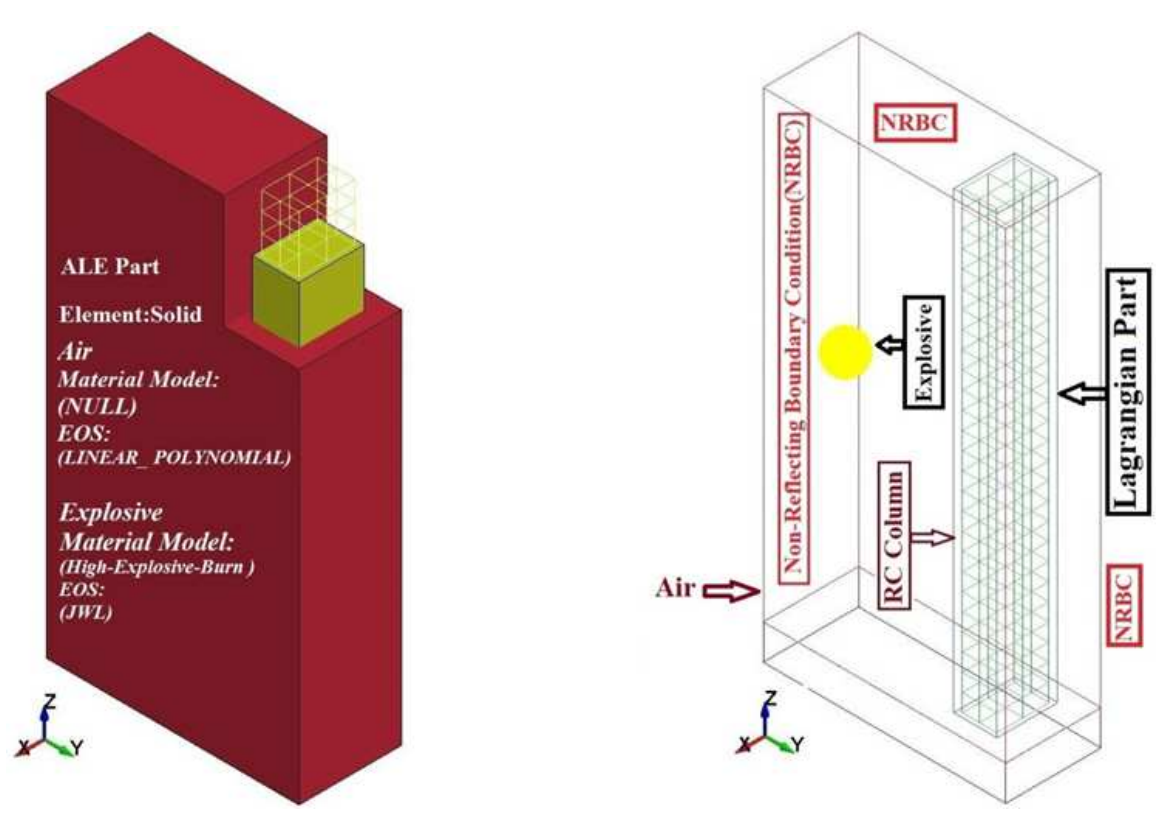

Fig. 3. Finite element model of blast load

\section{Material Models}

One of the biggest challenges associated with modeling the behavior of reinforced concrete is the difficulty of incorporating realistic material models that can represent the observable behavior of the physical system. In this study four material models are determined as follows:

\section{Concrete Material Model}

A wide variety of material models for concrete are exist in LS-DYNA library, some of the models are specialized and some of them are for general modeling of concrete. Concrete is known to be ductile in nature under hydrostatic pressure conditions and may be subjected to brittle failure in tension under impact loading conditions. LS-DYNA contains several material models that can be used for concrete; however the actual behavior of concrete under high detonation loads is extremely complicated. The constitutive material model Mat_Concrete_Damage_REL3 is used in this study. In this material model only one user input parameter; i.e., concrete strength is sufficient in the calibration process (Malvar et al., 1997; Schwer and Malvar, 2005). Table 2 gives the material properties of the concrete.

\section{Steel Material Model}

The steel rebar is modeled using material type 24 (MAT_PIECEWISE_LINEAR_ PLASTICITY). This material model represents steel reinforcement behavior, with plastic deformation, strain rate effects and failure. The input parameters for the MAT PIECEWISE LINEAR PLASTICITY model for longitudinal steel reinforcement and transverse steel reinforcement are tabulated in Table 3 and 4.
Table 2. Material properties of the concrete

\begin{tabular}{lll} 
& & \\
Mat_Concrete_Damage_Rel3 & & \\
Units (gram, $m$ m,, MPa) & & $\mathrm{PR}$ \\
$\mathrm{RO}$ & $\mathrm{f}_{\mathrm{c}}$ & 0.2 \\
0.0024 & 42 & \\
\hline
\end{tabular}

Table 3. Material properties of the longitudinal steel reinforcement

\begin{tabular}{llll}
\multicolumn{4}{c}{ reinforcement } \\
${ }^{*}$ MAT_PIECEWISE_LINEAR_PLASTICITY \\
Units (gram,mm,s,MPa) \\
RO & E & PR & \\
0.0078 & $2 \mathrm{e}+005$ & 0.3 & 450 \\
\hline
\end{tabular}

Table 4. Material properties of the transverse steel reinforcement

${ }^{*}$ MAT_PIECEWISE_LINEAR_PLASTICITY

Units (gram, mm, s, $\overline{M P a}$ )

\begin{tabular}{llll}
\hline RO & E & PR & $\mathrm{f}_{\mathrm{y}}$ \\
0.0078 & $2 \mathrm{e}+005$ & 0.3 & 400 \\
\hline
\end{tabular}

\section{Explosive Material Model}

The HIGH EXPLOSIVE BURN material model has chosen with 8th node finite elements. An Equation of State (EOS) is a formula describing the interconnection between various measurable properties of a system. The JWL equation of state (EOS) is used in the current research that represent in the below equation (Cheng et al., 2013):

$P=\left[A 1-\frac{\omega}{R_{1} V}\right] e^{-R_{1} V}+\left[B 1-\frac{\omega}{R_{2} V}\right] e^{-R_{2} V}+\frac{\omega E}{V}$

Where:

$A, B=$ Linear explosion parameters

$\omega, R_{1}$ and $R_{2}=$ Nonlinear explosion parameters 


$$
\begin{array}{ll}
\mathrm{V} & = \\
\mathrm{E} & \text { Relative volume } \\
& \text { Specific internal energy of every unit of } \\
\mathrm{P} & \text { mass } \\
= & \text { The pressure of the detonation products } \\
& \text { of high explosives }
\end{array}
$$

\section{Air Material Model}

Air is modeled with 8 nodes finite elements using the hydrodynamic material model MAT NULL and the 'Linear Polynomial' EOS (Mobaraki and Vaghefi, 2015). The pressure related to the energy can be expressed as follows:

$$
P=C_{0}+C_{1} \mu+C_{2} \mu^{2}+C_{3} \mu^{3}+\left(C_{4}+C_{5} \mu+C_{6} \mu^{2}\right) E_{0}
$$

$$
\mu=\frac{\rho}{\rho_{0}}-1
$$

where, $C_{0}, C_{1}, C_{2}, C_{3}, C_{4}, C_{5}$ and $C_{6}$ are constant, $\rho / \rho_{0}$ is the ratio of current density and $E_{0}$ is the initial internal energy per volume (LS-DYNA, 2015).

\section{Strain Rate Effects}

Materials such as steel and concrete exhibit greater strength when loaded at high rates and standards and manuals for blast-resistant design allow nominal component strengths to be increased by Dynamic Increase Factors to account for rate effects. In order to investigate reinforced concrete elements under blast loading conditions, strain rate effect must be considered.

\section{Concrete Strain Rate}

The ability of concrete to increase in strength as the strain rate increases is sometimes referred to as the Dynamic Increase Factor (DIF). The DIF is a function of the compressive or tensile strength at high strain rates versus the compressive or tensile strength of the concrete at static testing strain rates.

\section{Modified Strain Rate for Concrete in Compression}

The behavior of concrete under the effects of high strain rate has been extensively studied over the past few years. According to the Watstein (1953), the initial investigations carried out by Jones and Richard (1936) and Granville (Glanville et al., 1938) concluded that the compressive strength of concrete increased with the rate of loading. Watstein (1953) suggested that there was an increase of over $80 \%$ in compressive strength for concrete loaded at a strain rate of $10 \mathrm{~s}^{-1}$. In the CEB-FIB Model Code (Béton, 1993), the Dynamic Increase Factor (DIF) for compressive strength under high rates of loading may be estimated from the following equations:

$$
C D I F=\frac{f_{c}}{f_{c s}}=\left[\frac{\dot{\varepsilon}}{\dot{\varepsilon}_{c s}}\right]^{1.026 \alpha} \text { for } \dot{\varepsilon} \leq 30 S^{-1}
$$

$$
C D I F=\frac{f_{c}}{f_{c s}}=\gamma(\dot{\varepsilon})^{\frac{1}{3}} \text { for } \dot{\varepsilon}>30 S^{-1}
$$

Where:

$f_{c}=$ Dynamic compressive strength

$f_{c s}=$ Static compressive strength

$f_{c u}=$ Static cube strength

$$
\log \gamma=6.156 \alpha-0.49
$$

$$
\alpha=\frac{1}{5+\frac{3 f_{c u}}{4}}
$$

\section{Modified Strain Rate for Concrete in Tension}

Compared to other materials, concrete exhibits higher strain rate sensitivity under blast loading, due to scale size of the heterogeneity. Especially, the tensile strength exhibits a strong increase beyond loading rates in the order of $10 \mathrm{MPa} / \mathrm{s}$. For a given stress rate, the Dynamic Increase Factor (DIF) for tensile strength under high rates of loading may be estimated from the following equations:

$$
\begin{aligned}
& T D I F=\frac{f_{t}}{f_{t s}}=\left[\frac{\dot{\varepsilon}}{\varepsilon_{t s}^{\prime}}\right]^{\delta} \text { for } \dot{\varepsilon} \leq 1 S^{-1} \\
& T D I F=\frac{f_{t}}{f_{t s}}=\beta\left[\frac{\dot{\varepsilon}}{\varepsilon_{t s}^{\prime}}\right]^{\frac{1}{3}} \text { for } \dot{\varepsilon}>1 S^{-1}
\end{aligned}
$$

Where:

$f_{t}=$ Dynamic tensile strength

$f_{t s}=$ Static tensile strength:

$\beta=6 \delta-2$

$\delta=\frac{1}{10+\frac{8 f_{c}^{\prime}}{f_{c o}^{\prime}}}$

Where:

$f_{c}^{\prime}=$ Static uniaxial strength of concrete (in MPa)

$f_{c o}^{\prime}=10 \mathrm{MPa}$

\section{Dynamic Properties of Steel}

The stress-strain behavior of steel is particularly sensitive to the loading rate and this phenomenon is known as strain rate sensitivity. As far as energy absorption is concerned, the strain rate sensitivity plays an equally important role to that of the inertia effect of the material. It clearly reflects from the load-displacement curve of the material, which was tested under various uniaxial compression strain rates (Marsh and Campbell, 
1963). Malvar (1998) proposed another equation for steel reinforcing bars produced under ASTM standards. The Dynamic Increasing Factor (DIF), which is defined as the ratio of the dynamic to static yield stress, was used to represent the influence of strain rate on strength enhancement under dynamic conditions. To derive these equations Malvar (1998) used several test results available in the literature. For determining the yield strength and ultimate strength for reinforcing bars at different strain rates, he proposed the following formulation of the DIF:

$$
D I F={\frac{(\dot{\varepsilon})}{10^{-4}}}^{\alpha}
$$

Where, $f_{y}=$ Steel yield strength:

$$
\begin{aligned}
& \alpha=0.019-0.009 \frac{f_{y}}{414} \text { for ultimate stress } \\
& \alpha=0.074-0.040 \frac{f_{y}}{414} \text { for yield stress }
\end{aligned}
$$

\section{Verification of Numerical Models}

In fact, validated computational models can dramatically simplify the analysis process and greatly reduce the cost and time involving in physical testing. In this study column design was chosen based on previous research conducted by Baylot and Bevins (2007) on reinforced concrete columns under explosive loads. The column cross section was $85 \times 85 \mathrm{~mm}$ and the column free span length was $935 \mathrm{~mm}$. eight longitudinal rebar with the diameter of $7 \mathrm{~mm}$ was placed in the column. The longitudinal reinforcements were closed with stirrups with diameter of $3.35 \mathrm{~mm}$. Table 5 shows the material properties of the steel reinforcement and concrete and Fig. 4 shows peak displacement results obtained from current study and Baylot and Bevins (2007) study. The peak displacement estimated in the current study was $12 \mathrm{~mm}$ while the peak displacement in the Baylot and Bevins (2007) was $12.5 \mathrm{~mm}$. the residual displacement computed in the current study and experimental study was $6.3 \mathrm{~mm}$. The results show that the numerical model has a high level of agreement with experimental results done by Baylot and Bevins (2007).

\section{Residual Capacity $\left(P_{r}\right)$ Analysis Procedure}

The residual axial capacity index $\left(P_{r}\right)$ was defined as the axial compression capacity of a column in damage conditions. The numerical procedure used for generating residual capacity of RC column is illustrated in Fig. 5. This was achieved by applying a static axial load to the top of damaged column until the column fails.

\section{Derivation of Residual Axial Capacity Equations of $R C$ Columns}

The residual axial capacity of a RC column can be determined through numerical analysis performed on the detailed finite element models of the columns. In this study, the residual axial capacity index $\left(P_{r}\right)$ was defined as the axial compression capacity of a column in damage conditions. Parametric studies is performed to study the effects of column depth $(d)$, longitudinal reinforcement ratio $(\rho)$, transverse reinforcement ratio $\left(\rho_{s}\right)$, yield stress of longitudinal steel $\left(f_{y}\right)$, yield stress of transverse steel $\left(f_{y t}\right)$, column height $(H)$, column width $(w)$ and concrete strength $\left(f_{c}\right)$ on the residual capacity of RC columns under blast loads. The results obtained from this simulation are then used to arrange a laboratory based experiment to confirm the accuracy of residual axial capacity prediction capability of the numerical simulation models and vice versa.

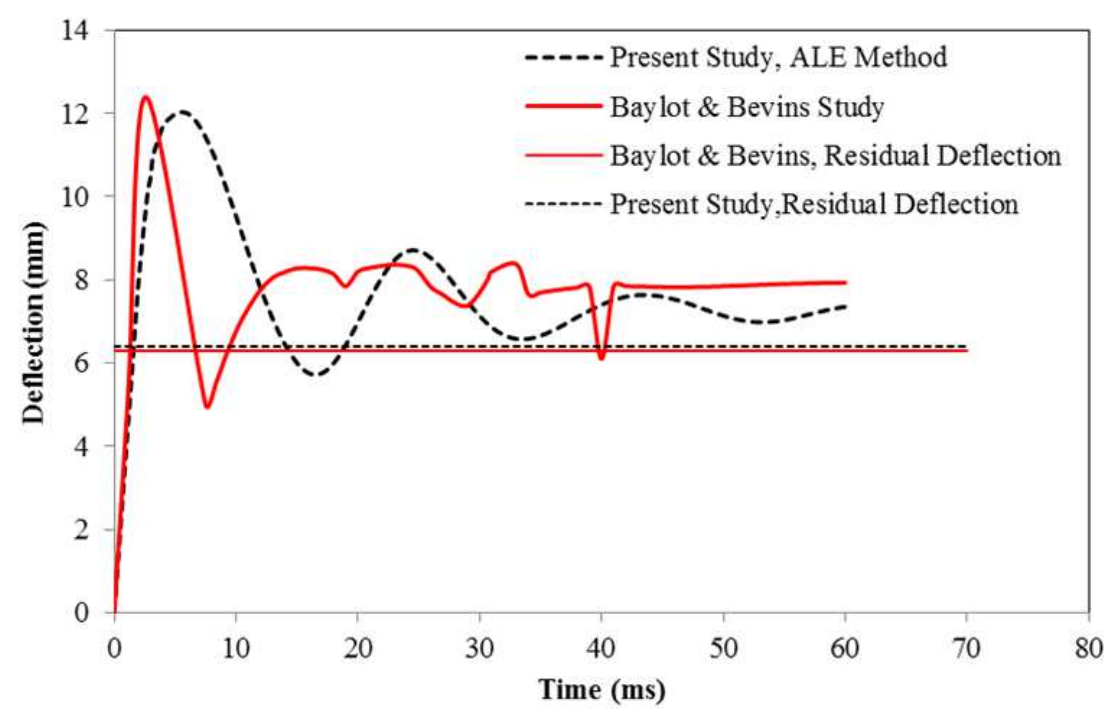

Fig. 4. Deflection-time histories at the middle height of the column (Baylot and Bevins, 2007) 


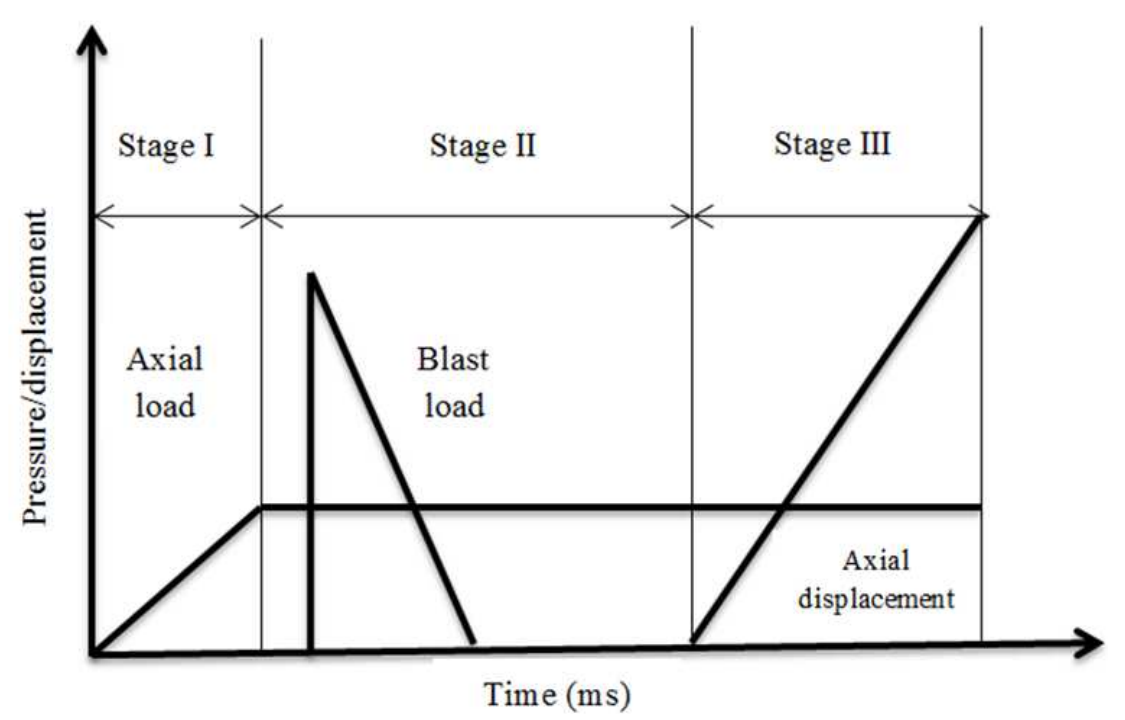

Fig. 5. Loading procedures to determine the residual axial load carrying capacity of the RC column

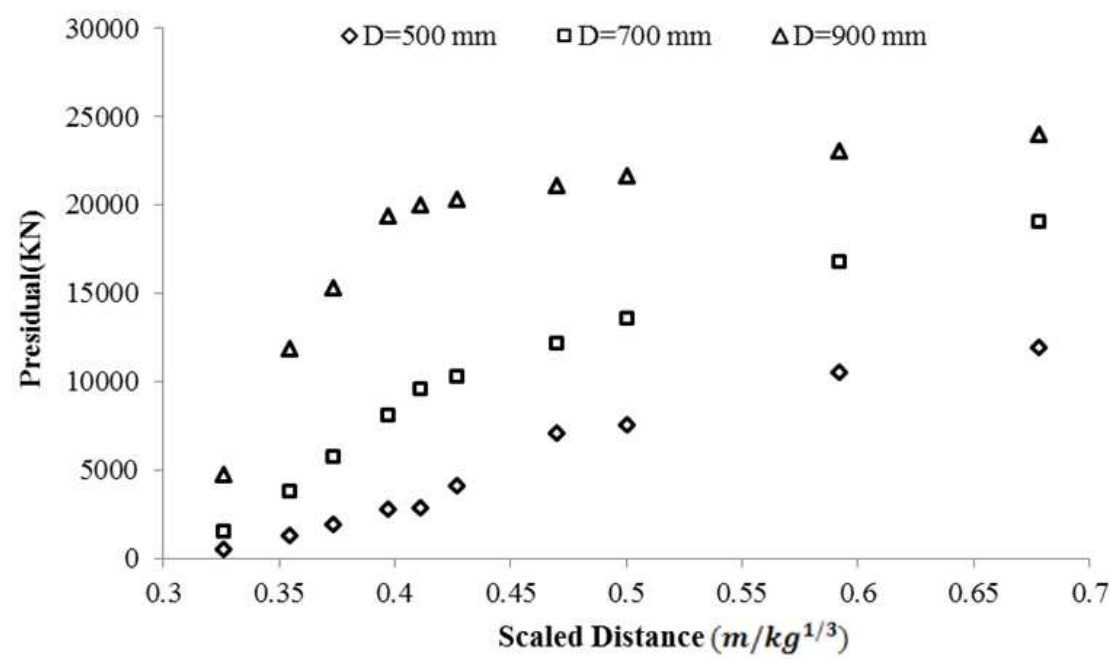

Fig. 6. Effects of column depth on the residual axial capacity of RC columns with different scaled distances

Table 5. Concrete and reinforcement rebar data used in the verification study (Baylot and Bevins, 2007)

\begin{tabular}{lll}
\hline Material & Material properties & Value \\
\hline Concrete & $f_{c u}$ & $42 \mathrm{MPa}$ \\
Longitudinal rebar & $f_{y}$ & $450 \mathrm{MPa}$ \\
& $U T S$ & $510 \mathrm{MPa}$ \\
& $\varepsilon_{f}$ & $18 \%$ \\
Transverse rebar & $f_{y t}$ & $400 \mathrm{MPa}$ \\
& $U T S$ & $610 \mathrm{MPa}$ \\
& $\varepsilon_{f}$ & $18 \%$ \\
\hline
\end{tabular}

\section{Columns with Different Depths}

The primary intention of the study is to determine the effects of column depth on the residual axial capacity of the RC columns under blast loads. Therefore, numerical simulations are conducted to study the influence of different column depth on the residual capacity of RC columns under blast loads. In order to consider the influence of column depth on the residual axial capacity of RC column, the numerical simulation results of three $\mathrm{RC}$ columns with different column depth, i.e., 500, 700 and $900 \mathrm{~mm}$ are derived. In these case studies, the column height and width is $4200 \mathrm{~mm}$ and $700 \mathrm{~mm}$ respectively. There are eight longitudinal reinforcements with diameter of $25 \mathrm{~mm}$ placed on the cross-section, the stirrup reinforcement rebar has a diameter of $12 \mathrm{~mm}$ and spaced at $200 \mathrm{~mm}$ between stirrup reinforcements along the column height. Concrete with compressive strength of $42 \mathrm{MPa}$ and longitudinal and transverse steel reinforcement with yield stress of 460 and $250 \mathrm{MPa}$ are used. Figure 6 shows the column depth efficiency as a function of 
residual capacity of $\mathrm{RC}$ column. It can be observed that with the increase of column depth, the residual axial capacity of RC column can be effectively increased as the scaled distance increases. From the results, it is obvious that a thicker column experiences more residual axial capacity under the same scaled distance. This means that a column with a larger depth can resist a bigger explosive load. The average residual axial capacity enhancement is approximately $71.9 \%$ for $\mathrm{RC}$ columns with different depth. The best fitted boundary surface for the residual capacity of RC column with different column depths is shown in Fig. 7.

$P_{\text {residual }}=0.1127+\left(d^{1.88}\right)\left(S^{1.14}\right)$

where, $P_{\text {residual }}$ is the residual axial load carrying capacity of RC column, $\mathrm{d}$ is the column depth in $\mathrm{mm}$ and $\mathrm{S}$ is the scaled distance in $\mathrm{m} / \mathrm{kg}^{1 / 3}$.

To confirm the precision of the generated formulae, a comparison of the residual axial capacity of RC columns obtained from the proposed formulae with the numerical results is accomplished and the results represent in the Fig. 8. It demonstrates that the proposed empirical formula is suitable for predicting residual capacity of RC columns and revealing a reasonably good agreement. The empirical formula developed in this research may be utilized to quickly check the residual capacity $\left(P_{\text {residual }}\right)$ in RC columns and obtain an initial educated guess about the performance of structural columns when exposed to certain blast loading.

\section{Columns with Different Longitudinal Reinforcement Ratio}

To investigate the effect of the longitudinal reinforcement ratio on the residual capacity of RC column under blast loads, three different longitudinal reinforcement ratios, namely $0.011,0.018$ and 0.028 $\mathrm{MPa}$, are studied. All the columns considered have the same dimension of $700 \times 500 \times 4400 \mathrm{~mm}$. The transverse reinforcement ratio and arrangement remain the same as defined in the first section. Material properties are assigned as $42 \mathrm{MPa}$ for concrete compressive strength and $460 \mathrm{MPa}$ and 250 $\mathrm{MPa}$ for the yield strength of the longitudinal and transverse reinforcement steel, respectively.

The comparisons of the residual capacity of RC column with different longitudinal reinforcement ratios are shown in Fig. 9. Besides the column depth, the reinforcement of the column could also have significant influence on the residual capacity of RC column. It designates that with the rise of the longitudinal reinforcement ratio, the residual capacity of RC columns will increase as the scaled distance increases. This is because increasing the longitudinal reinforcement ratio can considerably increase the bending strength of the RC column, but has little influence to the shear strength. The average residual capacity improvement is $36.3 \%$ for RC columns with different longitudinal reinforcement ratios. The fitted polynomial graph is then expressed in the form of surface plots in order to illustrate the residual capacity of RC column under explosion loads with different longitudinal reinforcement ratio as represent in the Fig. 10:

$P_{\text {residual }}=2.19 e 5 \times\left(\frac{1}{\rho}^{-0.45}\right)\left(S^{2.14}\right)$

where, $P_{\text {residual }}$ is the residual axial load carrying capacity of RC column $\rho$ is the longitudinal reinforcement ratios and $\mathrm{S}$ is the scaled distance in $\mathrm{m} / \mathrm{kg}^{1 / 3}$.

A comparison of the residual capacity of $\mathrm{RC}$ columns obtained from the proposed formulae with the numerical results is accomplished to verify the accuracy of the formula as represent in the Fig. 11. It demonstrates that the proposed empirical formula is suitable for predicting residual capacity of RC columns and revealing a reasonably good agreement. The validated equation can be used for quick assessment of existing RC column when blast loading is required to be considered especially to evaluate the blast resistant capacity of a critical building such as military buildings, government assets and etc.

\section{Columns with Different Transverse Reinforcement Ratio}

In this part, numerical simulations are carried out to estimate the residual axial capacity of the RC columns based on different transverse reinforcement ratio. The transverse reinforcement ratio for evaluating the residual capacity of RC column has been fluctuated between 0.0027 and 0.0075 . All the columns considered have the same dimension of $700 \times 500 \times 4400 \mathrm{~mm}$. The longitudinal reinforcement ratio and arrangement remain the same as defined in the first section. Material properties are assigned as $42 \mathrm{MPa}$ for concrete compressive strength and $460 \mathrm{MPa}$ and $250 \mathrm{MPa}$ for the yield strength of the longitudinal and transverse reinforcement steel, respectively. The comparisons of the residual capacity of the RC columns under different scaled distance and different transverse reinforcement ratios are given in Fig. 12. The results demonstrated that the residual capacity of $\mathrm{RC}$ column is increased by increasing transverse reinforcement ratio. Increasing the transverse reinforcement ratios can have a significant affect in reducing the deflection due to improved effective moment of inertia of the concrete section. The residual capacity improvement is near $17.6 \%$ in $\mathrm{RC}$ columns with different transverse reinforcement ratios. 


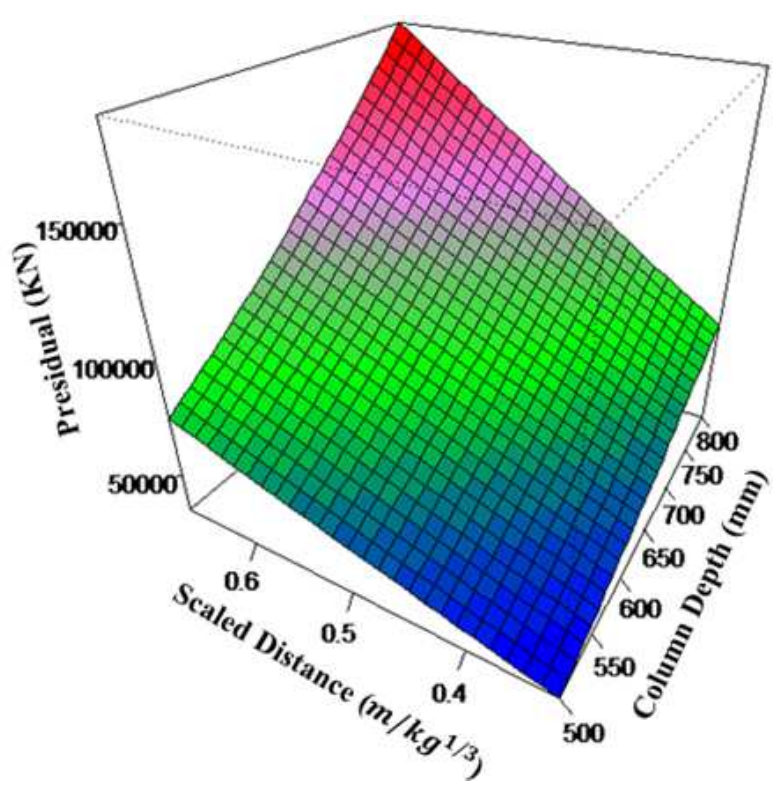

Fig. 7. The best fitted curve for the residual axial capacity of RC columns with different column depths

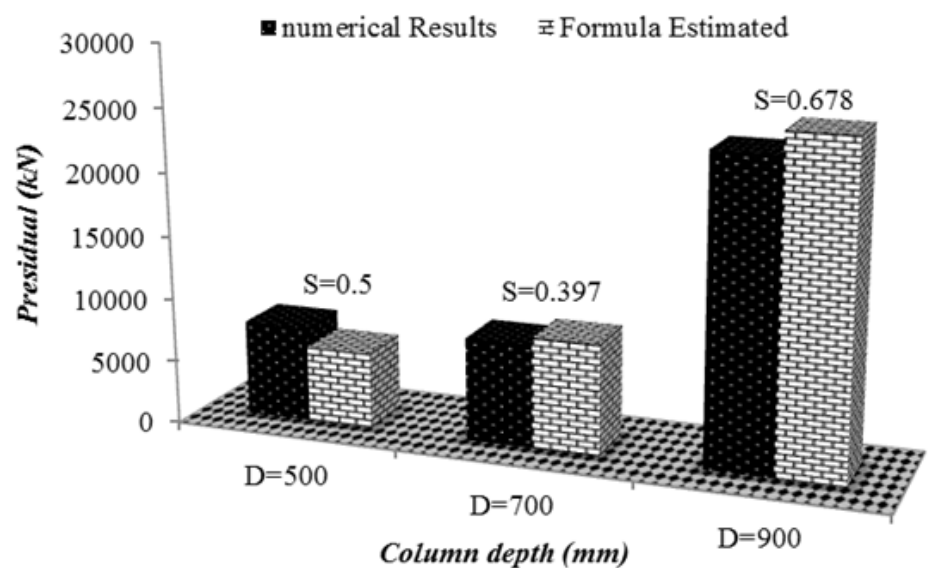

Fig. 8. Comparison of residual capacity of RC columns generated from numerical results and analytical formulae

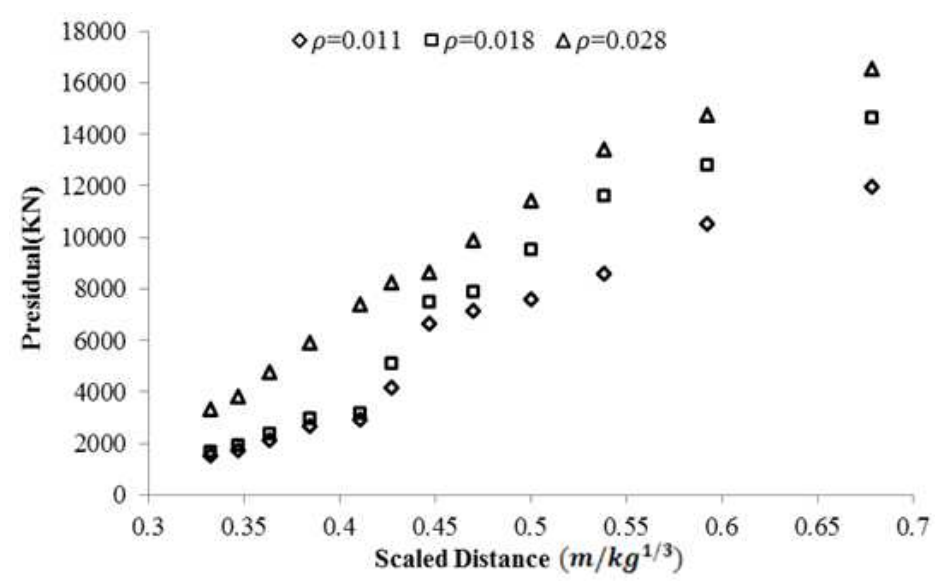

Fig. 9. Effects of longitudinal reinforcement ratios on the residual axial capacity of RC column with different scaled distance 


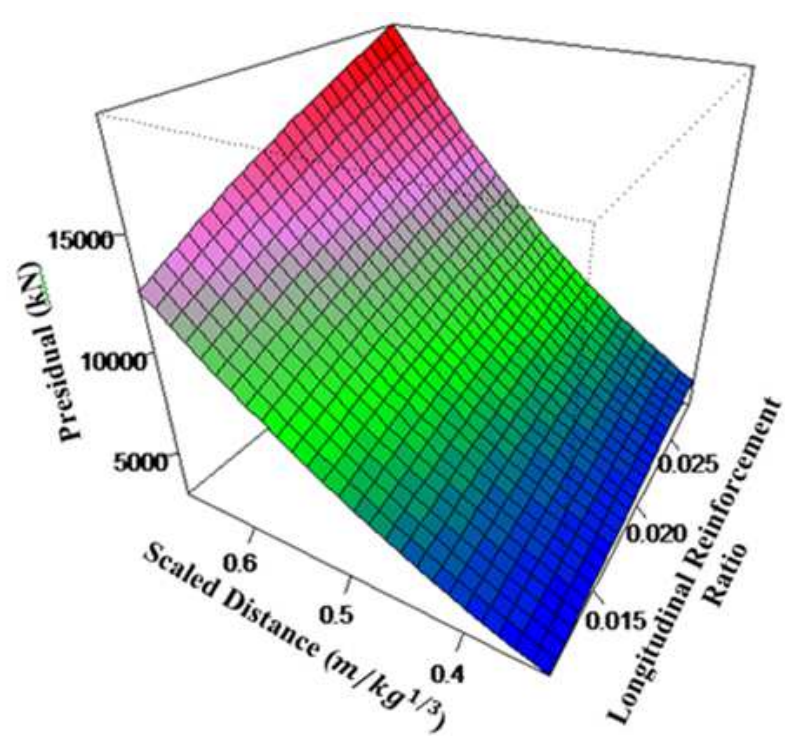

Fig. 10. The best fitted curve for the residual axial capacity of RC column with different longitudinal reinforcement ratios

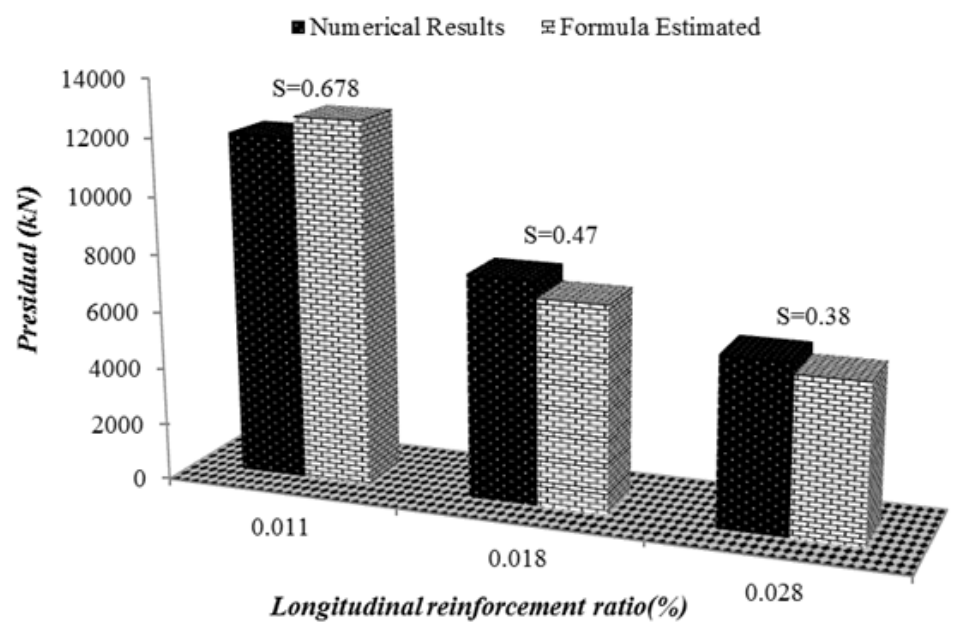

Fig. 11. Comparison of residual capacity of RC columns generated from numerical results and analytical formulae

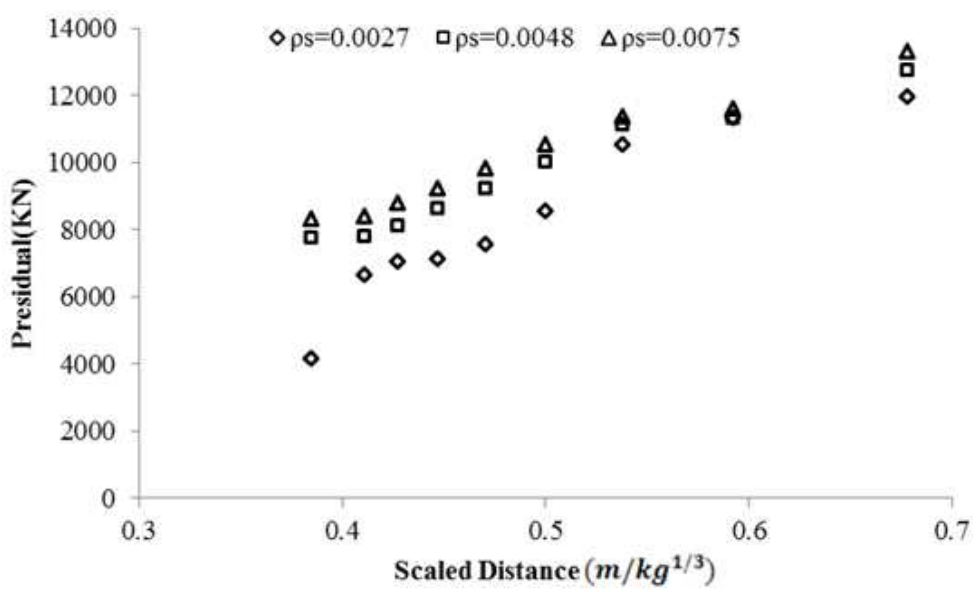

Fig. 12. Effects of transverse reinforcement ratios on the residual axial capacity of RC column with different scaled distances 


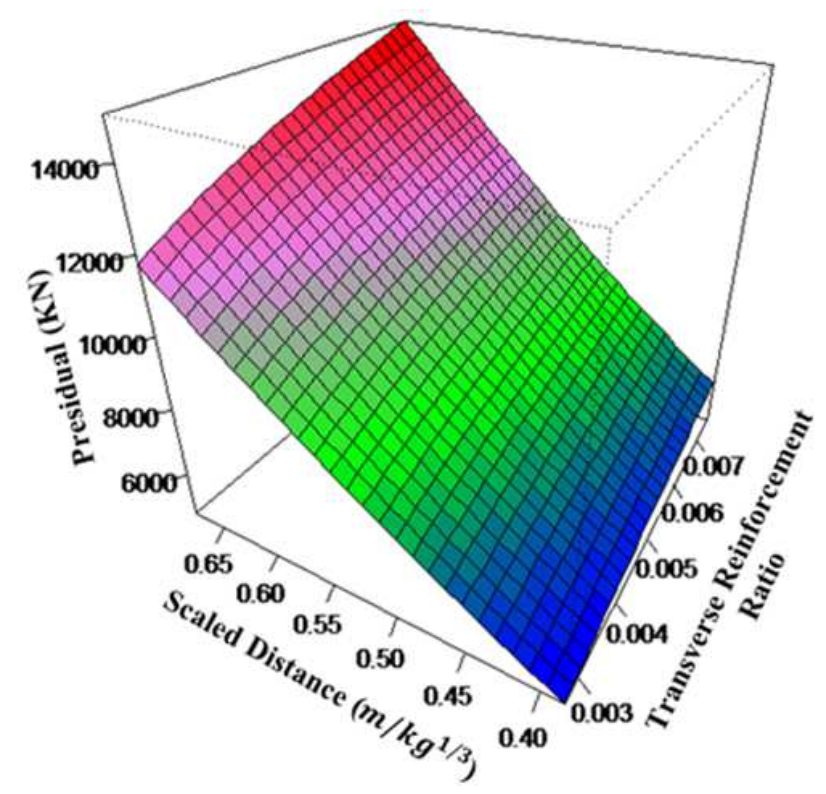

Fig. 13. The best fitted curve for the residual axial capacity of RC column with different transverse reinforcement ratios

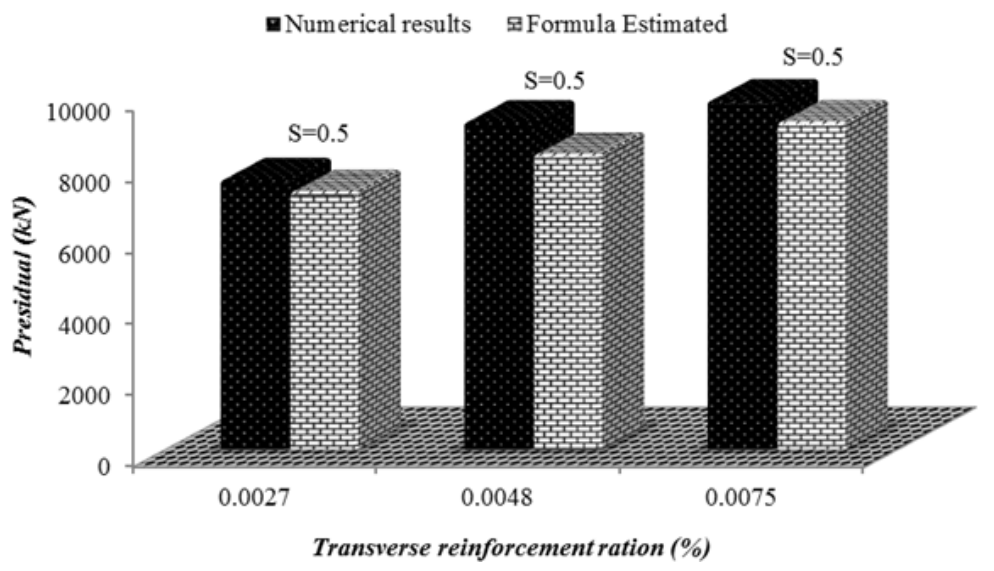

Fig. 14. Comparison of residual capacity of RC columns generated from numerical results and analytical formulae

The best fitted boundary surface for the residual capacity of RC column with different transverse reinforcement ratio is shown in Fig. 13 and the corresponding equation is given below:

$$
P_{\text {residual }}=88406 \times\left(\frac{1}{\rho s}^{-0.23}\right) \times\left(W^{1.6}\right)
$$

where, $P_{\text {residual }}$ is the residual axial load carrying capacity of RC columns, $\rho_{s}$ is the transverse reinforcement ratios and $\mathrm{S}$ is the scaled distance in $\mathrm{m} / \mathrm{kg}^{1 / 3}$.

To corroborate the correctness of the generated formulae, a comparison of the residual axial load carrying capacity of $\mathrm{RC}$ columns obtained from the proposed formulae with the numerical results is accomplished and the results represent in the Fig. 14. It establishes that the proposed empirical formula is suitable for predicting residual capacity of RC columns and revealing a reasonably good agreement. The empirical formula developed in this research may be utilized to quickly check the residual capacity $\left(P_{\text {residual }}\right)$ in $\mathrm{RC}$ columns and obtain an initial educated guess about the performance of structural columns when exposed to certain blast loading.

\section{Columns with Different Yield Stress of Longitudinal Steel}

Longitudinal steel strength is an important factor to determine the residual axial load carrying capacity of RC column. In order to examine the effect of yield stress of 
longitudinal steel on the residual axial load carrying capacity of RC column, various yield stress of longitudinal steel were tested as $400 \mathrm{MPa}, 460 \mathrm{MPa}$ and $550 \mathrm{MPa}$. All the columns considered have the same dimension of $700 \times 500 \times 4400 \mathrm{~mm}$. The longitudinal reinforcement ratio and arrangement remain the same as defined in the first section. The residual capacity of RC column with respect to the scaled distance and steel strength is shown in Fig. 15. It can be observed that under the same scaled distance, the residual capacity of $\mathrm{RC}$ columns increases as the steel strength increases. The results show that the columns with higher longitudinal steel strength had higher residual axial capacity to sustain the blast detonations. It can be concluded therefore that the stronger steel strength improves the RC column resistance to explosive load and the enhancement is about $21.4 \%$. The fitted polynomial graph is then expressed in the form of surface plots in order to illustrate the residual capacity of RC column under explosion loads with different longitudinal steel strength as represent in the Fig. 16:

$$
P_{\text {residual }}=1235.42+\left(f_{y}^{1.68}\right)\left(S^{2.5}\right)
$$

Where $P_{\text {residual }}$ is the residual axial load carrying capacity of RC columns, $f_{y}$ is longitudinal steel strength and $\mathrm{S}$ is the scaled distance in $\mathrm{m} / \mathrm{kg}^{1 / 3}$.

The accuracy of the predicted equation compared to the observed values in the numerical simulation that represent in the Fig. 17. It shows that the proposed empirical formula is suitable for predicting residual capacity of $\mathrm{RC}$ columns and revealing a reasonably good agreement.

\section{Columns with Different Yield Stress of Transverse Steel}

Based on the numerical simulations, residual capacity analyses of three RC columns which are the same in dimension and longitudinal steel strength but different in transverse steel strength under explosion load are carried out to study the effect of the transverse steel strength on the residual capacity of RC columns. Residual capacity of RC columns with different transverse steel strength of 250, 400 and 460 $\mathrm{MPa}$ are shown in Fig. 18. All the columns considered have the same dimension of $700 \times 500 \times 4400 \mathrm{~mm}$. The longitudinal and transverse reinforcement ratio and arrangement remain the same as defined in the first section. From Fig. 18, one could find that with the increase of the transverse steel strength, the residual capacity of the RC columns would slightly increase, as expected. It indicates the residual axial capacity of columns with higher transverse steel strength is able to resist more blast detonations. From the results, the percentage increase in residual axial capacity of RC column with different transverse steel strength is found to be $26 \%$. The best fitted boundary surface and counter plot for the residual capacity of RC column with different yield stress of transverse steel is shown in Fig. 19:

$$
P_{\text {residual }}=(2869.76) \times\left(f_{y t}^{0.4317}\right) \times\left(S^{2.2}\right)
$$

where, $P_{\text {residual }}$ is the residual axial load carrying capacity of RC columns, $f_{y}$ is transverse steel strength and $\mathrm{S}$ is the scaled distance in $m / \mathrm{kg}^{1 / 3}$.

The comparisons of numerical data and analytical formula, conducted in the current research program, shows that a reasonable accuracy can be achieved through the use of this equation as represent in the Fig. 20. The empirical formula developed in this research may be utilized to quickly check the residual capacity $\left(P_{\text {residual }}\right)$ in RC columns and obtain an initial educated guess about the performance of structural columns when exposed to certain blast loading.

\section{Columns with Different Width}

The difference in column width is considered in this study to evaluation of residual capacity of RC columns under blast loads. The columns width range is taken between $500 \mathrm{~mm}$ and $900 \mathrm{~mm}$ to investigate the column width effect on the residual capacity of the RC columns under extreme impulsive loads. In this study, the longitudinal and transverse steel strength are 460 and $250 \mathrm{MPa}$ respectively. In these case studies, the column height is $4200 \mathrm{~mm}$ and column depth is 700 $\mathrm{mm}$. The longitudinal and transverse reinforcement ratio and arrangement remain the same as defined in the first section. Figure 21 shows the effect of column width on the residual axial capacity of the RC columns with various scaled distances. It can be seen that residual axial load carrying capacity of RC columns increase with the rise in column width as the scaled distance increases. The results show that the residual axial capacity of RC column with low column width is less than that of a column with high column width. From the results, the percentage increase in residual axial capacity of $\mathrm{RC}$ column with different transverse steel strength is found to be $41 \%$. The best fitted boundary surface for the residual capacity of RC column with different width is shown in Fig. 22:

$$
P_{\text {residual }}=2382.1+\left(w^{1.68}\right)\left(S^{2.7}\right)
$$

where, $P_{\text {residual }}$ is the residual axial load carrying capacity of RC columns, $w$ is column width in $\mathrm{mm}$ and $\mathrm{S}$ is the scaled distance in $\mathrm{m} / \mathrm{kg}^{1 / 3}$. 


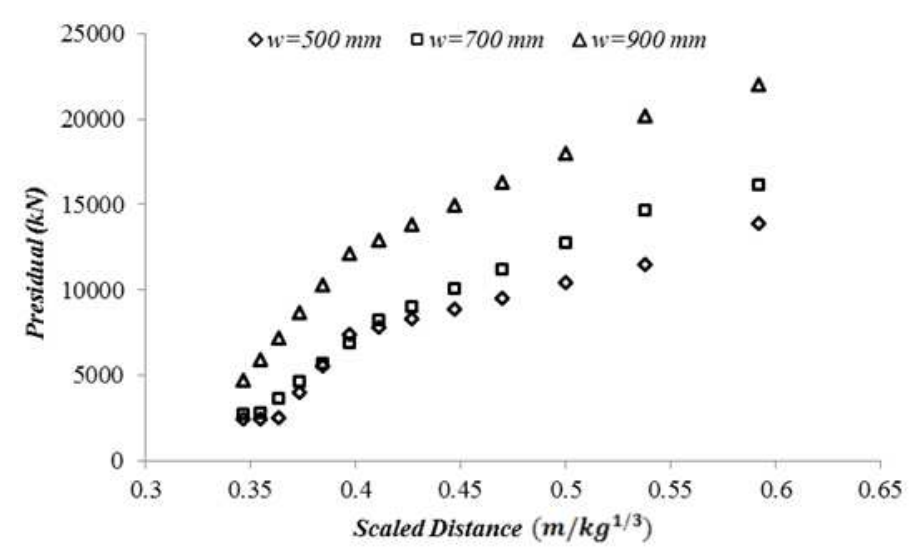

Fig. 21. Effects of column width on the residual axial capacity of RC column with different scaled distances

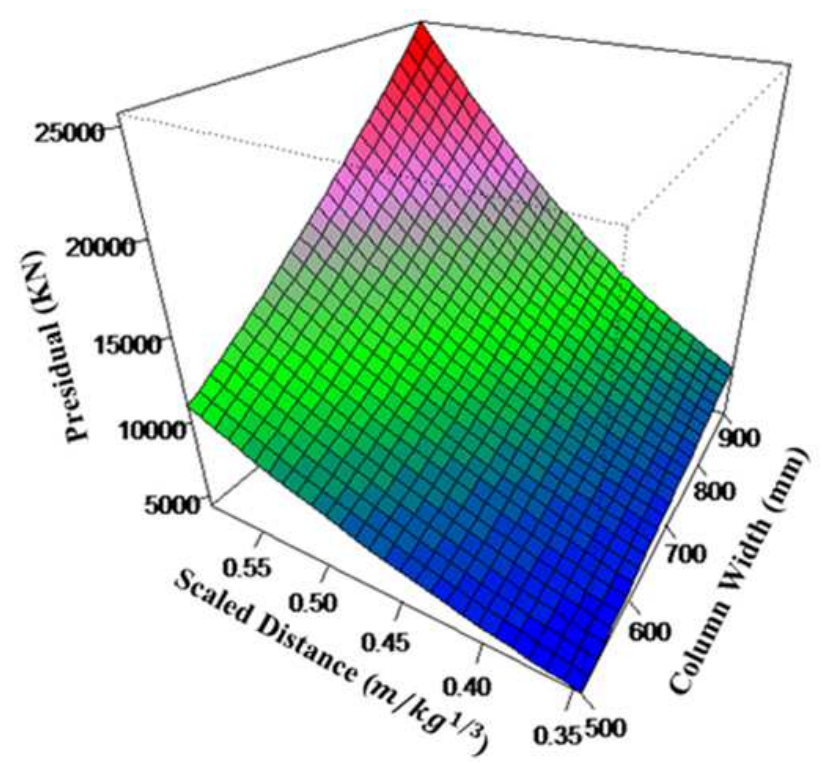

Fig. 22. The best fitted curve for the residual axial capacity of RC column with different columns width

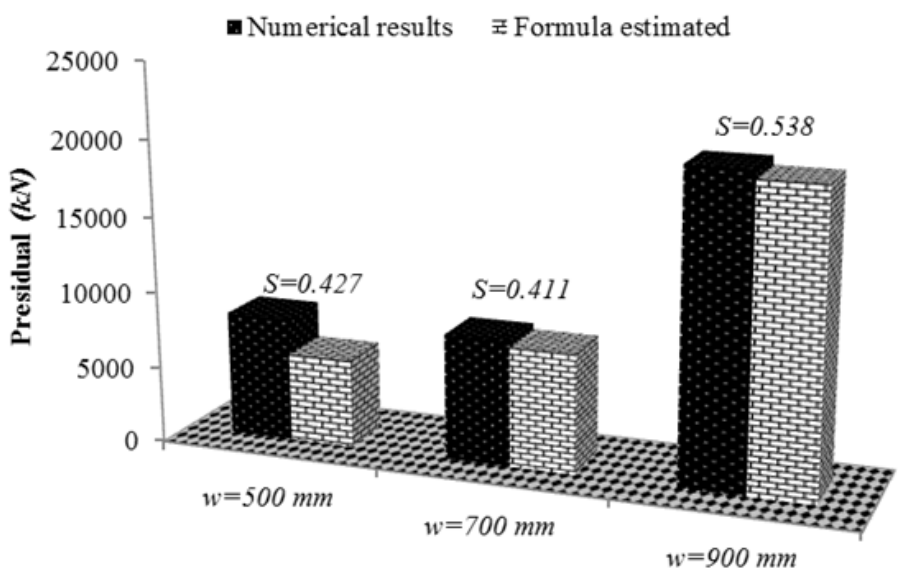

Column Width(mm)

Fig. 23. Comparison of residual capacity of RC columns generated from numerical results and analytical formulae 
To validate the exactness of the generated formulae, a comparison of the residual capacity of RC columns obtained from the proposed formulae with the numerical results is accomplished and the results represent in the Fig. 23. It demonstrations that the proposed empirical formula is suitable for predicting residual axial load carrying capacity of $\mathrm{RC}$ columns and revealing a reasonably good agreement. The empirical formula developed in this research may be utilized to quickly check the residual capacity (Presidual) in RC columns and obtain an initial educated guess about the performance of structural columns when exposed to certain blast loading.

\section{Columns with Different Height}

$\mathrm{RC}$ columns with different height of $3400 \mathrm{~mm}$, $4400 \mathrm{~mm}$ and $5400 \mathrm{~mm}$ are analyzed to compare the residual axial load carrying capacity of the RC columns under blast loads due to changes in column height. In this case study, the column depth is $500 \mathrm{~mm}$ and column width is $700 \mathrm{~mm}$. The longitudinal and transverse reinforcement ratio and arrangement remain the same as defined in the first section. Figure 24 displays the effects of column height on the residual capacity of RC column with different scaled distance. The result showed that with rising column height, the residual capacity of the RC columns decreased as scaled distance decreases. The residual axial load carrying capacity increment may be marginal when the column height is high. In fact reduction in longitudinal steel strength had significant effect on residual capacity of RC columns at smaller scaled distances. The residual capacity of RC columns increases by $34.4 \%$ when the column height decreased from $5400 \mathrm{~mm}$ to $3400 \mathrm{~mm}$. The fitted polynomial graph is then expressed in the form of surface plots in order to illustrate the residual capacity of RC column under explosion loads with different column height as represent in the Figure 25:

$$
P_{\text {residual }}=4271.6+\left(H^{1.26}\right)\left(S^{4.13}\right)
$$

where, $P_{\text {residual }}$ is the residual axial load carrying capacity of RC columns, $(H)$ is column height in $m m$ and $\mathrm{S}$ is the scaled distance in $\mathrm{m} / \mathrm{kg}^{1 / 3}$.

To corroborate the precision of the generated formulae, a comparison of the residual capacity of RC columns obtained from the proposed formulae with the numerical results is accomplished and the results represent in the Fig. 26. It demonstrates that the proposed empirical formula is suitable for predicting residual capacity of $\mathrm{RC}$ columns and revealing a reasonably good agreement. The empirical formula developed in this research may be utilized to quickly check the residual capacity in RC columns and obtain an initial educated guess about the performance of structural columns when exposed to certain blast loading.

\section{Columns with Different Concrete Strength}

The effect of concrete strength is the last parameter investigated in this series. In this section the influence of concrete strength on residual capacity of the RC columns is evaluated. The concrete strength can have a significant effect in increasing the residual axial load carrying capacity of the RC columns under explosive loads. The concrete strength is varied between 32 to $52 \mathrm{MPa}$. In these case studies, the column height is $4200 \mathrm{~mm}$, the column width is 700 $\mathrm{mm}$ and column depth is $500 \mathrm{~mm}$. The longitudinal and transverse steel strength are 460 and $250 \mathrm{MPa}$ respectively. The longitudinal and transverse reinforcement ratio and arrangement remain the same as defined in the first section.

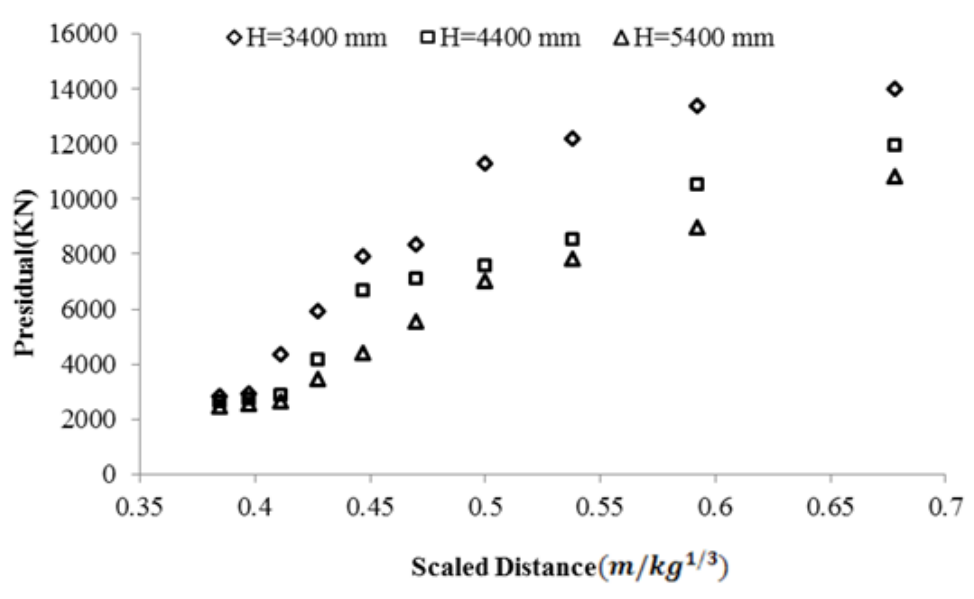

Fig. 24. Effects of column height on the residual axial capacity of RC column with different scaled distance 


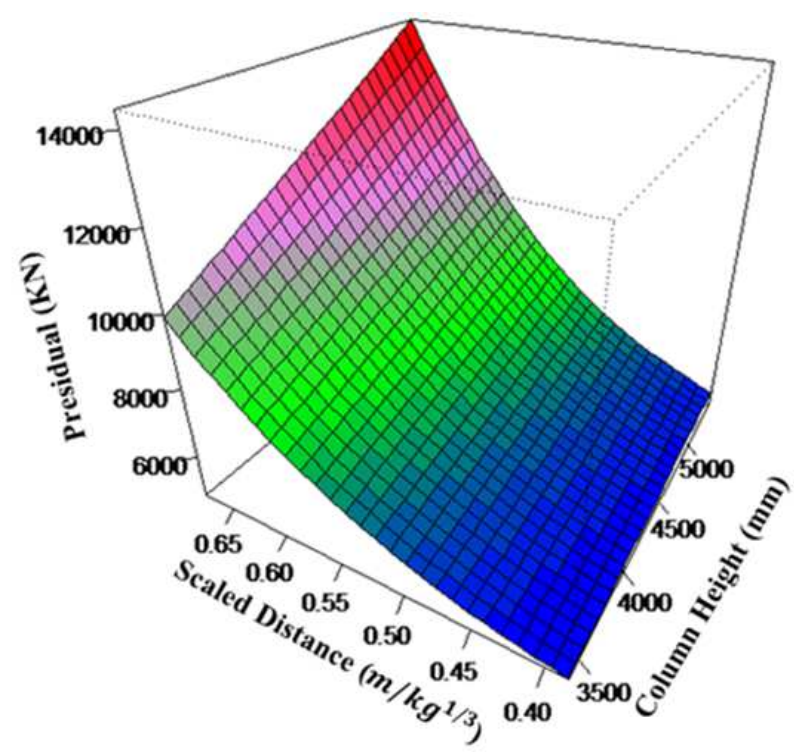

Fig. 25. The best fitted curve for the residual axial capacity of RC column with different columns height

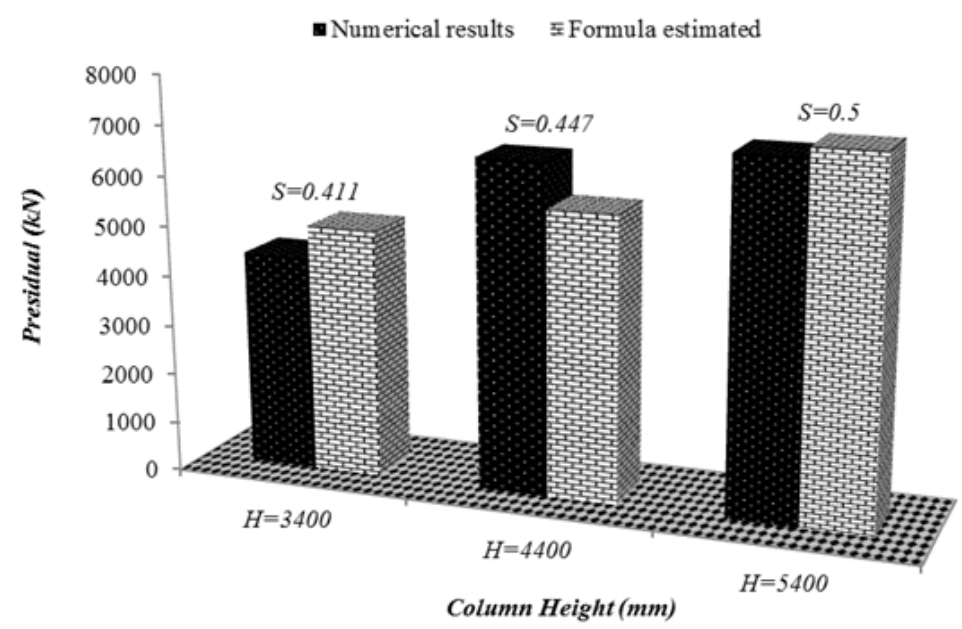

Fig. 26. Comparison of residual capacity of RC columns generated from numerical results and analytical formulae

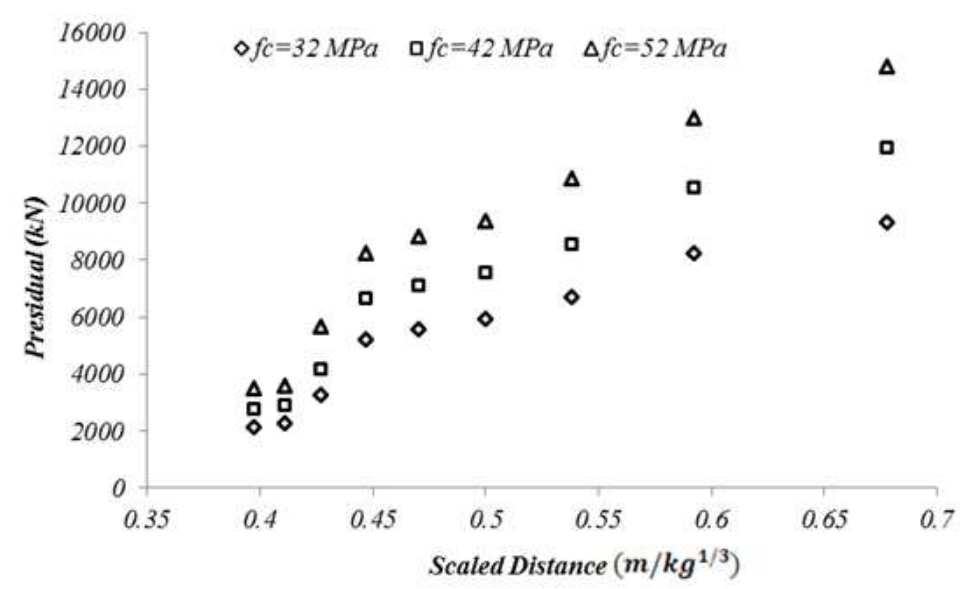

Fig. 27. Effects of concrete strength on the residual axial capacity of RC column with different scaled distance 


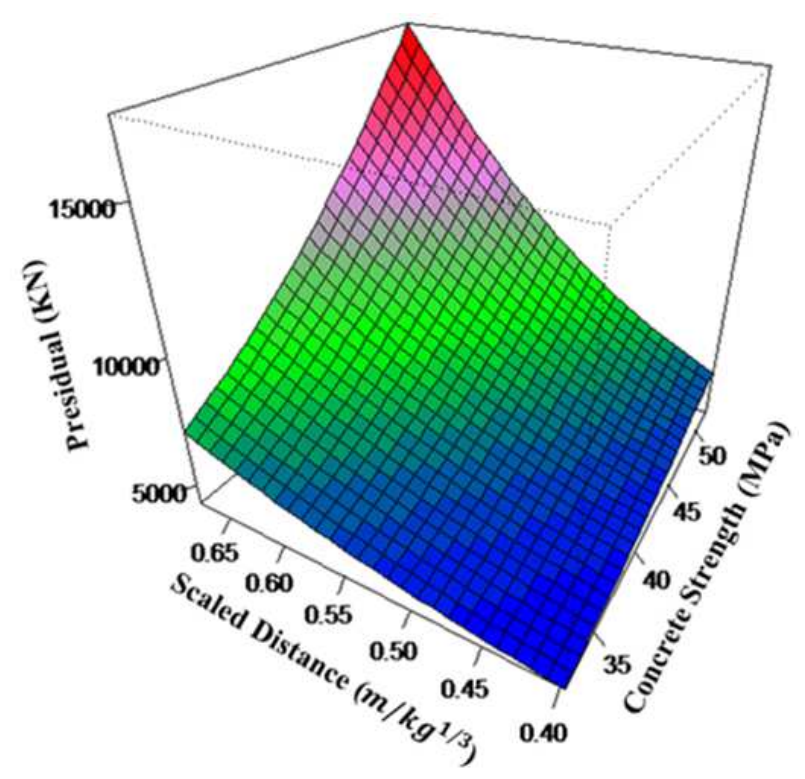

Fig. 28. The best fitted curve for the residual axial capacity of RC column with different concrete strength

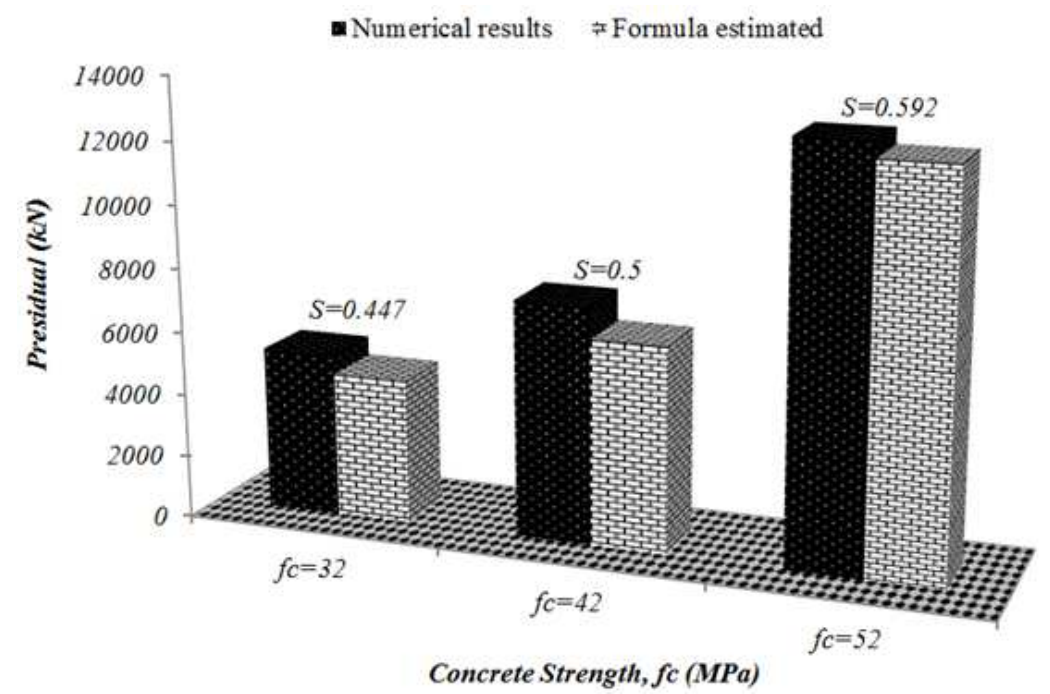

Fig. 29.Comparison of residual capacity of RC columns generated from numerical results and analytical formulae

Figure 27 shows the effect of concrete strength on the residual capacity of the RC columns. It can be seen that the concrete strength efficiency of residual axial load carrying capacity of RC columns increases with augmenting concrete strength. Generally, residual capacity of RC columns improves with increasing concrete strength. The residual capacity of RC columns increased around $37.4 \%$ by increasing of the concrete strength from $32 \mathrm{MPa}$ to $52 \mathrm{MPa}$. The best fitted boundary surface for the residual capacity of RC column with different concrete strength is shown in Fig. 28:

$$
P_{\text {residual }}=3570.62+\left(f_{c}^{2.729}\right)\left(W^{3.216}\right)
$$

where, $P_{\text {residual }}$ is the residual axial load carrying capacity of RC columns, $f_{c}$ is concrete strength in $M P a$ and $\mathrm{S}$ is the scaled distance in $\mathrm{m} / \mathrm{kg}^{1 / 3}$.

To approve the exactitude of the generated formulae, a comparison of the residual capacity of $\mathrm{RC}$ columns obtained from the proposed formulae with the numerical results is accomplished and the results represent in the Fig. 29. It determines that the proposed empirical formula is suitable for predicting residual capacity of RC columns and revealing a reasonably good agreement. The empirical formula developed in this research may be utilized to quickly check the residual capacity in RC columns and obtain an initial educated guess about the performance of structural columns when exposed to certain blast loading. 


\section{Conclusion}

This research performed the numerical analysis of the residual axial load carrying capacity of reinforced concrete column that was subjected to explosive loads. In this study, Numerical model was prepared using LSDYNA to predict the residual capacity of RC column under blast loads. A three-dimension numerical model, including explosive, air, reinforcement, concrete and Arbitrary Lagrange-Euler approach, is developed. The accuracy of the numerical models was verified using the findings of experimental data obtained by other researchers. Intensive simulations are carried out to investigate the effects of column depth $(d)$, longitudinal reinforcement ratio $(\rho)$, transverse reinforcement ratio $\left(\rho_{s}\right)$, yield stress of longitudinal steel $\left(f_{y}\right)$, yield stress of transverse steel $\left(f_{y t}\right)$, column height $(H)$, column width $(w)$ and concrete strength $\left(f_{c}\right)$ on the residual capacity of RC columns subjected to explosion load. It is found that column depth and longitudinal reinforcement ratio have significant effects on the residual axial load carrying capacity of reinforced concrete column under blast loads. Increasing column depth and longitudinal reinforcement ratio that provides better confinement to concrete are very effective in the residual capacity of RC column subjected to blast loads. Based on intensive numerical simulation data, analytical expressions are derived to predict residual capacity of RC column in terms of the charge weight, column depth, column height, column width, longitudinal reinforcement ratio and yield stress of longitudinal reinforcement. The data collected from this research are being used to improve the knowledge of how structures will respond to a blast event and improve finite element models for predicting the residual capacity of RC column under blast loads.

\section{Acknowledgement}

The authors would like to thank Universiti Kebangsaan Malaysia for financial support under grant ERGS-1-2013-PK04-UKM-02-1 and FRGS-1-2015TK01-UKM-02-4.

\section{Author's Contributions}

The authors state the contributions made by each author in the preparation, development and publication of this manuscript.

\section{Conflict of Interests}

The authors declare that there is no conflict of interests regarding the publication of this paper.

\section{References}

Bao, X. and B. Li, 2010. Residual strength of blast damaged reinforced concrete columns. Int. J. Impact Eng., 37: 295-308. DOI: 10.1016/j.ijimpeng.2009.04.003

Baylot, J.T. and T.L. Bevins, 2007. Effect of responding and failing structural components on the airblast pressures and loads on and inside of the structure. Comput. Struct., 85: 891-910. DOI: $10.1016 /$ j.compstruc.2007.01.001

Béton, C.E.I.D., 1993. CEB-FIP model code 1990: design code, Telford.

Bischoff, P. and S. Perry, 1991. Compressive behaviour of concrete at high strain rates. Mater. Struct., 24: 425-450. DOI: $10.1007 / \mathrm{BF} 02472016$

Cheng, D., C. Hung and S. Pi, 2013. Numerical simulation of near-field explosion." Journal of Applied Science and Engineering 16(1): 61-67.

Cui, J., Y. Shi, Z.X. Li and L. Chen, 2015. Failure analysis and damage assessment of RC columns under close-in explosions. J. Performance Constructed Facilities. DOI: 10.1061/(ASCE)CF.1943-5509.0000766

Donea, J. and A. Huerta, 2004. Arbitrary LagrangianEulerian methods. Encyclopedia Comput. Mech.

Ellingwood, B.R. and D.O. Dusenberry, 2005. Building design for abnormal loads and progressive collapse. Comput.-Aided Civil Infrastr. Eng., 20: 194-205. DOI: $10.1111 / \mathrm{j} .1467-8667.2005 .00387 . x$

Flanagan, D. and T. Belytschko, 1981. A uniform strain hexahedron and quadrilateral with orthogonal hourglass control. Int. J. Numerical Meth. Eng., 17: 679-706. DOI: $10.1002 / \mathrm{nme} .1620170504$

Fujikake, K. and P. Aemlaor, 2013. Damage of reinforced concrete columns under demolition blasting. Eng. Struct., 55: 116-125. DOI: $10.1016 /$ j.engstruct.2011.08.038

Glanville, W.H., G. Grime, E.N. Fox and W.W. Davies, 1938. An investigation of the stresses in reinforced concrete piles during driving. HM Stationery Office.

Haufe, A., K. Weimar and U. Göhner, 2004. Advanced airbag simulation using fluid-structure-interaction and the Eulerian method. LS-DYNA. LS-DYNA Anwenderforum Conference. Bamberg.

Jayasooriya, R., D.P. Thambiratnam, N.J. Perera and V. Kosse, 2011. Blast and residual capacity analysis of reinforced concrete framed buildings. Eng. Struct., 33: 3483-3495. DOI: 10.1016/j.engstruct.2011.07.011

Jones, P.G. and F. Richart, 1936. The effect of testing speed on strength and elastic properties of concrete. Proceedings.

LS-DYNA, 2015. Keyword user's manual V971, CA: Livermore Software Technology Corporation (LSTC), Livermore, California. 
Malvar, L.J., 1998. Review of static and dynamic properties of steel reinforcing bars. ACI Mater. J., 95: 609-616.

Malvar, L.J., J.E. Crawford, J.W. Wesevich and D. Simons, 1997. A plasticity concrete material model for DYNA3D. Int. J. Impact Eng., 19: 847-873. DOI: $10.1016 / \mathrm{S} 0734-743 X(97) 00023-7$

Malvar, L.J. and C.A. Ross, 1998. Review of strain rate effects for concrete in tension. ACI Mater. J., 95: 735-739.

Marsh, K. and J. Campbell, 1963. The effect of strain rate on the post-yield flow of mild steel. J. Mechan. Phys. Solids 11: 49-63. DOI: $10.1016 / 0022-5096(63) 90007-3$

Mobaraki, B. and M. Vaghefi, 2015. Numerical study of the depth and cross-sectional shape of tunnel under surface explosion. Tunnell. Underground Space Technol., 47: 114-122. DOI: $10.1016 /$ j.tust.2015.01.003

Mutalib, A.A. and H. Hao, 2011. Development of P-I diagrams for FRP strengthened RC columns. Int. J. Impact Eng., 38: 290-304. DOI: 10.1016/j.ijimpeng.2010.10.029

Mutalib, A.A. and H. Hao, 2011. Numerical analysis of FRP-composite-strengthened RC panels with anchorages against blast loads. J. Performance Constructed Facilities, 25: 360-372. DOI: 10.1061/(ASCE)CF.1943-5509.0000199

Roller, C., C. Mayrhofer, W. Riedel and K. Thoma, 2013. Residual load capacity of exposed and hardened concrete columns under explosion loads. Eng. Struct., 55: 66-72.

DOI: $10.1016 /$ j.engstruct.2011.12.004

Schwer, L.E. and L.J. Malvar, 2005. Simplified concrete modeling with* MAT_CONCRETE_DAMAGE_REL3. JRI LSDyna User Week.

Shi, Y., H. Hao and Z.X. Li, 2008. Numerical derivation of pressure-impulse diagrams for prediction of $\mathrm{RC}$ column damage to blast loads. Int. J. Impact Eng., 35: $1213-1227$. DOI: 10.1016/j.ijimpeng.2007.09.001

Shi, Y. and M.G. Stewart, 2015. Spatial reliability analysis of explosive blast load damage to reinforced concrete columns. Struct. Safety, 53: 13-25. DOI: 10.1016/j.strusafe.2014.07.003
Stoker, H.C., 1999. Developments of the arbitrary lagrangian-eulerian method in non-linear solid mechanics applications to forming processes. Universiteit Twente.

Tai, Y., T. Chu, H. Hu and J. Wu, 2011. Dynamic response of a reinforced concrete slab subjected to air blast load. Theoretical Applied Fract. Mechan., 56: 140-147. DOI: 10.1016/j.tafmec.2011.11.002

Wang, J. and M. Gadala, 1997. Formulation and survey of ALE method in nonlinear solid mechanics. Finite Elements Anal. Design, 24: 253-269. DOI: $10.1016 / \mathrm{S} 0168-874 \mathrm{X}(96) 00061-3$

Watstein, D., 1953. Effect of straining rate on the compressive strength and elastic properties of concrete. J. Proc.

Weerheijm, J. and J. Van Doormaal, 2007. Tensile failure of concrete at high loading rates: new test data on strength and fracture energy from instrumented spalling tests. Int. J. Impact Eng., 34: 609-626. DOI: 10.1016/j.ijimpeng.2006.01.005

Wijesundara, G. and S. Clubley, 2015a. Damage state identification for reinforced concrete columns in uplift due to internal building detonations. Eng. Struct., 127: 804-823.

DOI: 10.1016/j.engstruct.2016.07.051

Wijesundara, L.M. and S.K. Clubley, 2015b. Residual axial capacity of reinforced concrete columns subject to internal building detonations. Int. J. Struct. Stability Dynam., 16: 1550050-1550050. DOI: $10.1142 / \mathrm{S} 0219455415500509$

Wijesundara, L.M. and S.K. Clubley, 2016. Numerical modelling of reinforced concrete columns subject to coupled uplift and shear forces induced by internal explosions. Struct. Infrast. Eng., 12: 171-187. DOI: $10.1080 / 15732479.2014 .1002502$

Wu, K.C., B. Li and K.C. Tsai, 2011. Residual axial compression capacity of localized blast-damaged RC columns. Int. J. Impact Eng., 38: 29-40.

DOI: 10.1016/j.ijimpeng.2010.09.002 